\title{
INFLUÊNCIA DO USO E OCUPAÇÃO DO SOLO NA QUALIDADE DA ÁGUA DO RIO CATOLÉ GRANDE, ITAPETINGA, BAHIA
}

Lídia Raíza Sousa Lima Chaves Trindade - lidiaraiza@hotmail.com

Universidade Estadual do Sudoeste da Bahia

Pedro Augusto Ferraz e Silva - pedroaugsto@outlook.com

Universidade Estadual do Sudoeste da Bahia

Romário Oliveira de Santana - engenheiro.romario@ hotmail.com

Universidade Estadual do Sudoeste da Bahia

Natália Andrade Silvão - naty_andrade18@hotmail.com

Universidade Estadual do Sudoeste da Bahia

Alison Silva dos Santos - alisonss@outlook.com

Universidade Estadual do Sudoeste da Bahia

Flávia Mariani Barros - mariamariani@yahoo.com.br

Universidade Estadual do Sudoeste da Bahia 


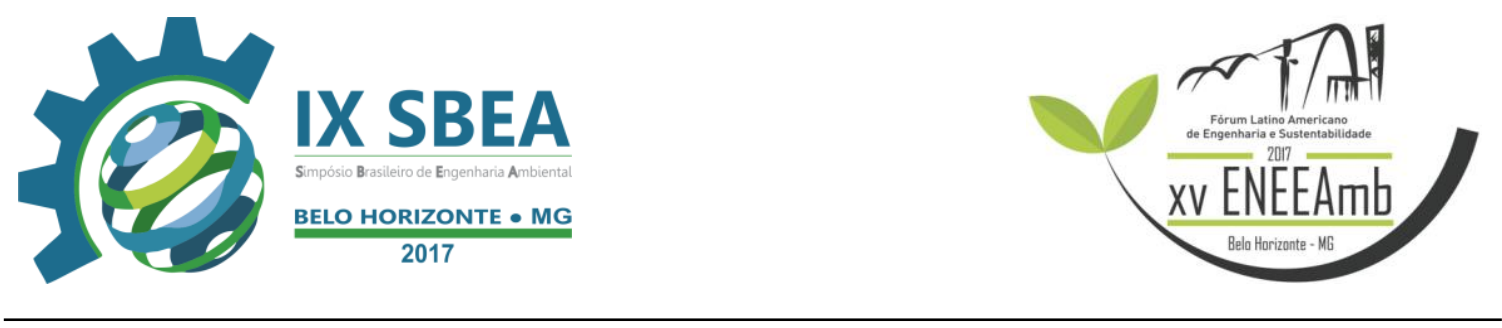

\section{RESUMO}

O presente estudo teve como objetivo a avaliação da qualidade da água do Rio Catolé Grande, localizado no município de Itapetinga, por meio da quantificação de variáveis físico-químicas, antes e após a contribuição de fontes de poluição. As coletas foram realizadas à montante e à jusante do rio em relação ao perímetro urbano, com uma frequência de amostragem mensal, de agosto a novembro de 2015. Foram coletadas amostras de 15 a $20 \mathrm{~cm}$, na calha central do rio, em cada mês avaliado. Os parâmetros físico-químicos avaliados foram: $\mathrm{pH}$, condutividade elétrica $(\mathrm{CE})$, turbidez, oxigênio dissolvido (OD) e sólidos totais dissolvidos (STD). Das variáveis observadas, todas diferiram estatisticamente entre os pontos pelo teste de Tukey a 5\% de probabilidade. A CE e o OD no ponto 2, se encontram fora dos padrões estabelecidos pela Companhia de Tecnologia de Saneamento Ambiental (CETESB) e Resolução CONAMA 357, respectivamente. As demais variáveis ( $\mathrm{pH}$, turbidez e sólidos totais), apresentaram resultados satisfatórios antes e após o perímetro urbano.

Palavras-chave: Monitoramento ambiental, parâmetros físico-químicos, recursos hídricos.

\section{INTRODUÇÃO/OBJETIVO}

A agricultura intensiva apresenta diferentes impactos ambientais na qualidade da água, é necessário, portanto, o monitoramento de diversos indicadores de qualidade. A maioria dos contaminantes químicos presentes em águas subterrâneas e superficiais está relacionada às fontes industriais e agrícolas. A variedade é enorme, com destaque para os agrotóxicos, compostos orgânicos voláteis e metais (HU; KIM, 1994).

A ocupação do solo interfere diretamente nos recursos hídricos, bem como, na sua gestão, pois o uso inadequado pode originar processos erosivos, compactação, aumento da salinidade do solo, assoreamento de corpos d'água e perdas em termos qualitativos e quantitativos (SILVA et al., 2010).

O uso de indicadores físico-químicos da qualidade da água consiste no emprego de variáveis que se correlacionam com as alterações ocorridas no manancial, sejam essas de origem antrópica ou natural. Deste modo, percebe-se que os cursos de água de 


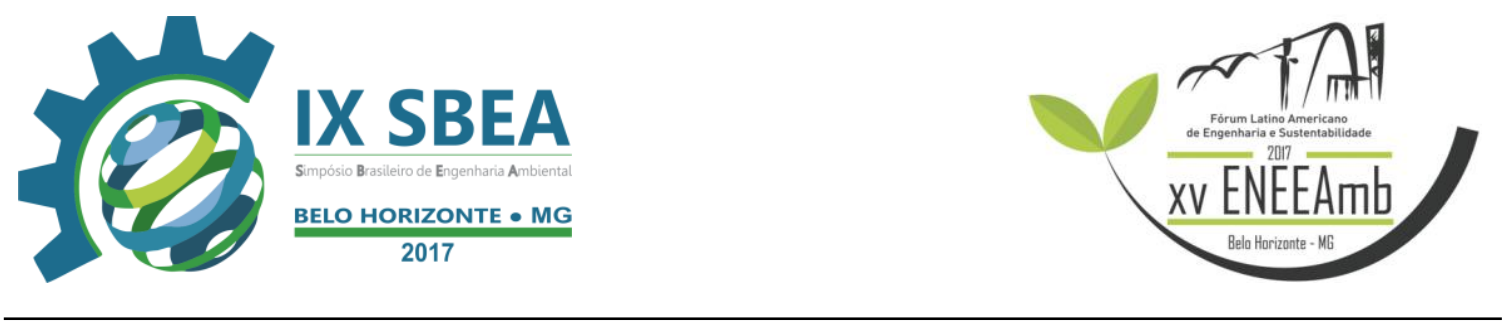

uma bacia hidrográfica são afetados pelo uso e ocupação do solo e por contaminantes despejados nos cursos d'água (BRAGA et al., 2005).

No intuito de minimizar os problemas que afetam a qualidade da água, faz-se necessário uma gestão dos recursos hídricos que sejam mais eficientes e contemplem não só as maiores bacias hidrográficas, como também as menores que na sua maioria são responsáveis pelo abastecimento de uma grande parte da população. De acordo com Barreto et al. (2014), o monitoramento dos corpos de água, tanto qualitativo quanto quantitativo, é de suma importância, principalmente para os que são utilizados como meio de abastecimento deste recurso para a população, pois, além de se evitar possíveis agravantes à saúde pública, podem promover planos ou projetos que visem à recuperação dos corpos d'água já intensamente degradados pelas atividades antrópicas.

Segundo Barros (2011), a qualidade da água pode ser representada por meio de diversas variáveis que traduzem as suas principais características físicas, químicas e biológicas. Inserido nesse contexto, o monitoramento limnológico trata especificamente da qualidade da água dos ecossistemas aquáticos continentais, incluindo rios e lagos (WETZEL, 2001). Assim, abrange tecnicamente a coleta periódica associada à análise de dados e informações de qualidade da água para propósitos de efetivo gerenciamento dos ecossistemas aquáticos (BISNAS, 1990). Dentre os fatores de importância para a avaliação da qualidade da água destacam-se o $\mathrm{pH}$, a condutividade elétrica, a temperatura, o oxigênio dissolvido, o nitrato, dentre outros (GOMES et al., 2011).

Nesse sentido, o objetivo do presente estudo será a avaliação da qualidade da água do Rio Catolé Grande, localizado no município de Itapetinga, Bahia, por meio da quantificação de variáveis, antes e após a contribuição de fontes de poluição.

\section{METODOLOGIA}

O local em que foi realizado o presente estudo está situado no rio Catolé Grande, sendo este pertencente à bacia hidrográfica do rio Pardo no Estado da Bahia. A bacia está contida entre os paralelos (8375000 e 8300000s) e entre os meridianos (300000 e 380000w) em coordenadas UTM. Composta pelos municípios de Vitória da Conquista, Itambé, Barra do Choça, Planalto, Caatiba, Nova Canaã e Itapetinga. As amostras foram 


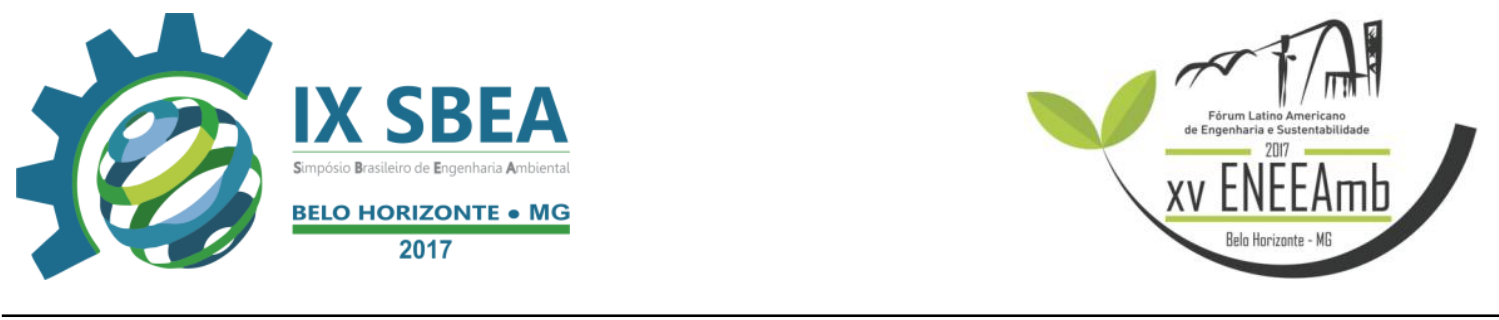

coletadas à montante e à jusante do rio em relação ao perímetro urbano do município de Itapetinga (Figura 1).

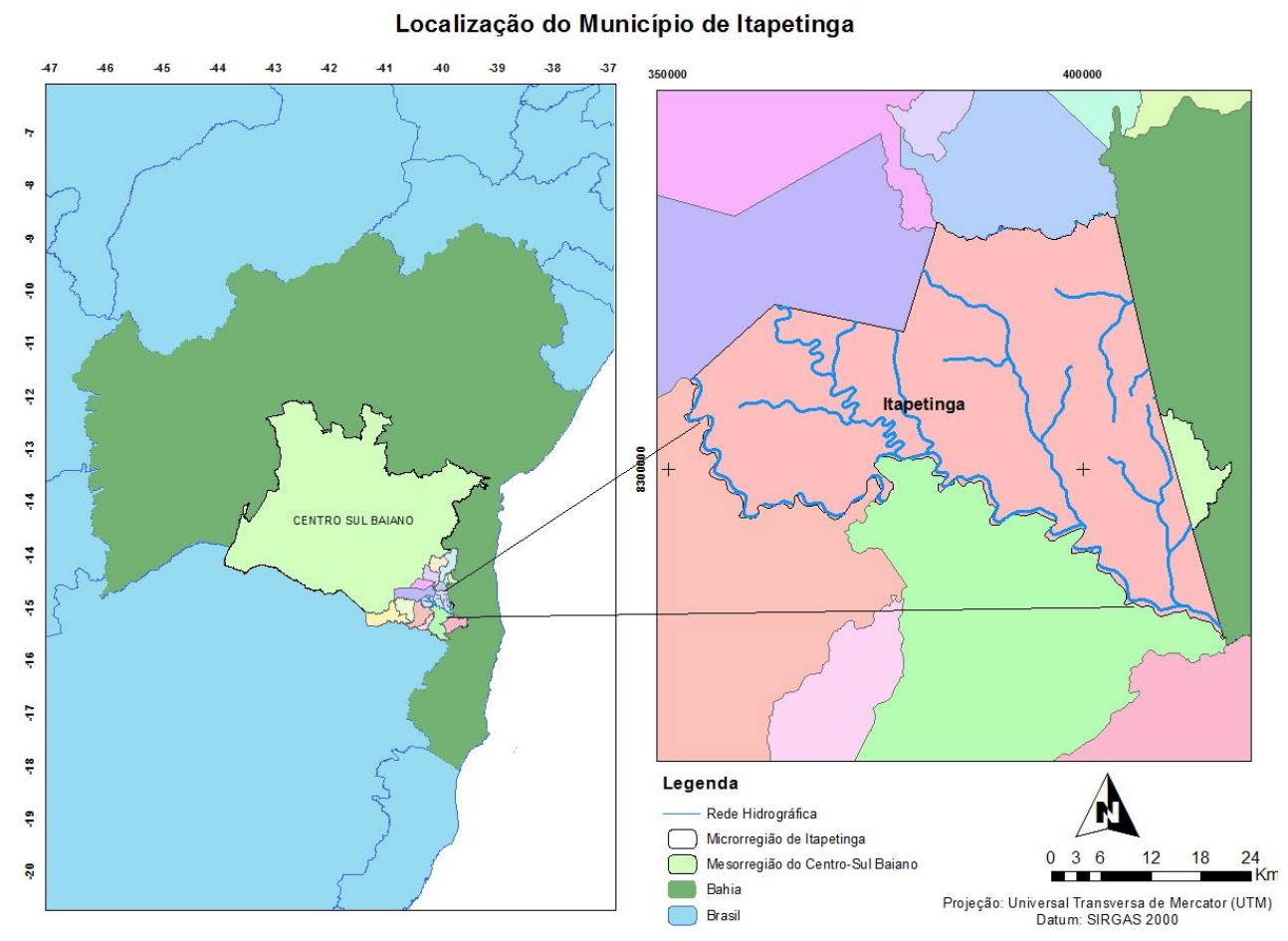

Figura 1. Localização do município de Itapetinga e sua rede hidrográfica.

Fonte. Elaborada pelos autores.

A frequência de amostragem foi mensal, perfazendo um total de quatro coletas, abrangendo o período de agosto a novembro de 2015. A amostragem foi realizada, segundo metodologia da CETESB (1988), na seção delimitada para o estudo no Rio Catolé Grande, referente às diferentes épocas. Foram coletadas amostras de 15 a $20 \mathrm{~cm}$ da superfície, no intuito de evitar a entrada de possíveis contaminantes superficiais, na calha central do rio, em cada mês avaliado. Após a coleta, as amostras de água foram acondicionadas em caixas de isopor e transportadas ao Laboratório de Dispersão de Poluentes da Universidade Estadual do Sudoeste da Bahia - Campus Itapetinga.

Os parâmetros físico-químicos avaliados foram: $\mathrm{pH}$, condutividade elétrica, turbidez, oxigênio dissolvido e sólidos totais dissolvidos. Em cada amostra de água coletada, as variáveis físico-químicas foram quantificadas segundo metodologias descritas em MATOS (2004), baseadas em APHA (2005). 


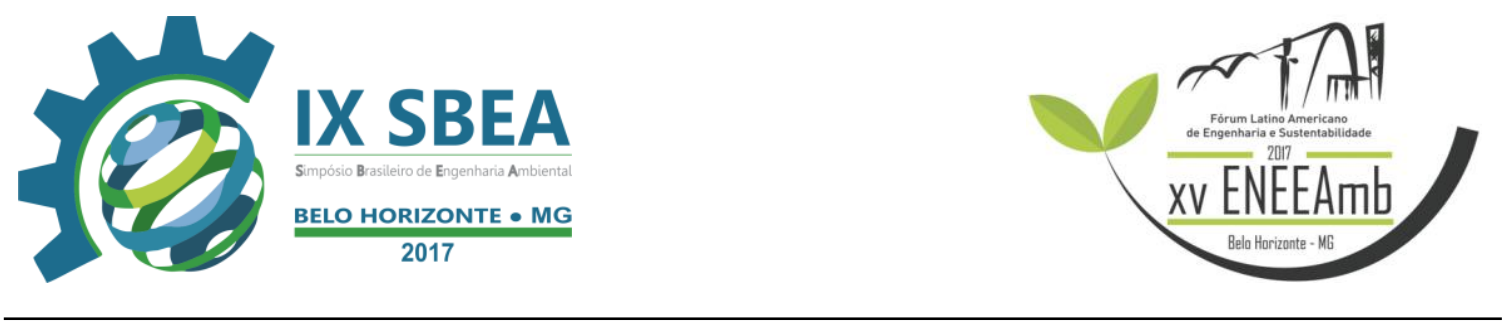

Para determinação do potencial hidrogeniônico, foi utilizado o método eletrométrico, com peagâmetro marca Digimed, modelo DM - 22. A condutividade da água foi obtida por meio de condutivímetro marca Digimed, modelo DM - 32. A variável turbidez foi determinada pelo método nefelométrico, utilizando-se um turbidímetro, Marca Digimed, modelo DM-TU - 0 a 1000 UNT. As concentrações de oxigênio dissolvido foram obtidas pelo método químico de Winkler, modificado pela ázida de sódio, que compreende diversas fases. E para determinação das concentrações de sólidos totais, foi utilizado o método gravimétrico.

A partir dos resultados obtidos foi realizado a ANOVA e posteriormente o teste de Tukey a 5\% de probabilidade, com emprego do software SAEGED - Sistema para Análises Estatísticas-Versão 9.1, para constatar se houve diferença significativa entre os valores das variáveis nos diferentes pontos de amostragem. Obtiveram-se as variáveis estatísticas.

\section{RESULTADOS E DISCUSSÃO}

Os resultados podem ser observados na tabela abaixo, onde estão apresentados os valores médios das variáveis da seção transversal do Rio Catolé Grande, em diferentes meses, a partir da metodologia de coleta adotada, CETESB (1988).

Tabela1. Características físico-químicas, antes e após o perímetro urbano de Itapetinga.

\begin{tabular}{lcccc}
\hline \multicolumn{1}{c}{ Análise (Ponto 1) } & Mês 01 & Mês 02 & Mês 03 & Mês 04 \\
& $06 / 08 / 2015$ & $11 / 09 / 2015$ & $08 / 10 / 2015$ & $05 / 11 / 2015$ \\
\hline $\mathrm{pH}$ & 8,51 & 9,02 & 8,44 & 7,86 \\
Cond. Elétrica $\left(\mu \mathrm{S} \mathrm{cm}^{-1}\right.$ ) & 96,41 & 117,71 & 81,36 & 95,57 \\
Turbidez $(\mathrm{NTU})$ & 6,78 & 4,38 & 3,51 & 2,35 \\
Sólidos Totais $\left(\mathrm{mg} \mathrm{L}^{-1}\right)$ & 92,33 & 64,67 & 69,67 & 79,00 \\
Oxigênio Dissolvido $\left(\mathrm{mg} \mathrm{L}^{-1}\right)$ & 6,48 & 6,05 & 7,18 & 5,01 \\
\hline \multicolumn{1}{c}{ Análise (Ponto 2) } & Mês 01 & Mês 02 & Mês 03 & Mês 04 \\
& $06 / 08 / 2015$ & $11 / 09 / 2015$ & $08 / 10 / 2015$ & $05 / 11 / 2015$ \\
& & & & \\
\hline pH & 8,63 & 7,70 & 7,43 & 7,38 \\
Cond. Elétrica $\left(\mu \mathrm{S} \mathrm{cm}^{-1}\right)$ & 115,45 & 126,35 & 120,72 & 130,97 \\
Turbidez $(\mathrm{NTU})$ & 4,34 & 3,85 & 3,17 & 4,17 \\
Sólidos Totais $\left(\mathrm{mg} \mathrm{L}^{-1}\right)$ & 94,67 & 67,33 & 91,00 & 97,00 \\
Oxigênio Dissolvido $\left(\mathrm{mg} \mathrm{L}^{-1}\right)$ & 3,09 & 2,11 & 6,63 & 1,01 \\
\hline
\end{tabular}




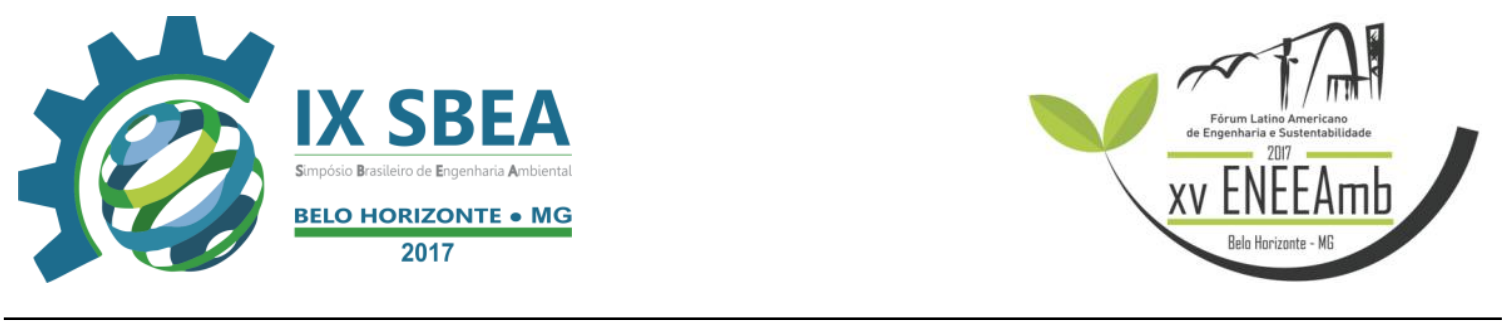

Os valores de pH da seção do Rio Catolé nos pontos 1 e 2 apresentaram pequenas variações. Verifica-se que o $\mathrm{pH}$ da água foi alcalino, oscilando entre 8,51 a 7,86, com maior valor no mês de setembro, igual a 9,02 para o ponto 1 e 8,63 a 7,38 para o segundo ponto, apresentando maior valor no mês de agosto, correspondente a 8,63. Os valores de pH atendem a Resolução CONAMA 357/05, a qual estabelece o valor mínimo em 6,0 e máximo em 9,0 para as águas doces de Classe 2. Segundo Von Sperling (1996) a alcalinidade no meio aquático pode estar associada à proliferação de vegetais, pois, com o aumento das taxas fotossintéticas, há consumo de gás carbônico e, portanto, diminuição do ácido carbônico da água e consequente aumento do $\mathrm{pH}$.

Barreto (2013), analisando a qualidade da água também do Rio Catolé Grande em uma seção transversal em diferentes épocas em 2011, evidenciou que os valores de pH atendem a Resolução CONAMA 357/05, a qual estabelece o valor mínimo em 6,0 e máximo em 9,0 para as águas doces de Classe 2, corroborando com o resultado encontrado no presente trabalho.

O valor médio de CE encontrado foi de $97,76 \mu \mathrm{S} \mathrm{cm}^{-1}$ para o ponto 1, dentro do limite de $100 \mu \mathrm{S} \mathrm{cm} \mathrm{cm}^{-1}$, valor estabelecido pela Companhia de Tecnologia de Saneamento Ambiental (CETESB), já que, as resoluções CONAMA 357/05 e 430/11, não estabelecem valores para condutividade elétrica. Em contrapartida, para o mês de setembro, o valor de CE foi acima do valor estabelecido, $117,71 \mu \mathrm{S} \mathrm{cm}^{-1}$, indicando um aumento da concentração de elementos dissolvidos responsáveis pelo aumento da condutividade elétrica. $\mathrm{O}$ mesmo ocorreu para o ponto 2 , em todos os meses de coleta, o que evidencia a má qualidade do rio após o perímetro urbano. Isso se deve principalmente aos efluentes domésticos e industriais lançados sem tratamento no local que, provavelmente, ao serem decompostos, aumentam a concentração de íons na água. Brigante e Espínola (2003) afirmam que, em geral, pode-se considerar que as águas mais poluídas apresentam maior condutividade elétrica devido ao aumento de conteúdo mineral.

Para turbidez, os valores no ponto 1 variaram de 6,78 a 2,35. O maior valor encontrado foi no mês de agosto, indicando maior interatividade com ações antrópicas neste mês, uma vez que a turbidez é significativamente afetada pelas condições hidrológicas do ambiente. No ponto após a área urbana, os valores de turbidez variaram 


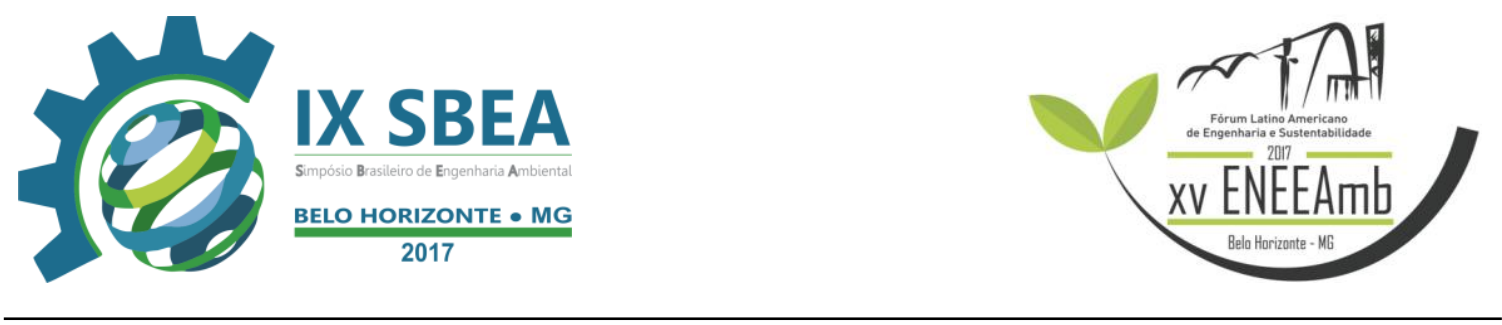

de 4,34 a 4,17 NTU. É possível inferir que o Rio Catolé se apresenta na condição de qualidade água doce classe 1, segundo a Resolução no 357 do CONAMA (BRASIL, 2005), para a variável turbidez, pois não excedeu o valor médio de 40 NTU.

Os valores obtidos para sólidos totais foram $76,42 \mathrm{mg} \mathrm{L}^{-1}$ e $87,50 \mathrm{mg} \mathrm{L}^{-1}$ no ponto 1 e 2, respectivamente. Os valores encontrados mostram que a contribuição dos sólidos neste ambiente aquático, provavelmente, é de origem natural, provenientes do arraste de partículas que desagregam do solo e chegam por meio do escoamento superficial. A média obtida do ponto após o perímetro urbano foi superior, áreas com maior atividade agrícola, processos de erosão, descargas de galerias pluviais, lançamentos de estações de tratamento de água e efluentes, aumentam a probabilidade de acréscimo de sólidos. Os parâmetros turbidez e sólidos totais refletem como o uso e ocupação do solo afeta os cursos d'água, os usos como solo exposto, urbano e agropecuário, principal atividade econômica do município, é uma fonte direta de sedimentos, produzindo altos valores de turbidez e sólidos totais no corpo hídrico.

O valor médio de concentração de oxigênio para o ponto 1 foi de $6,18 \mathrm{mg} \mathrm{L}^{-1}$, valor dentro do limite estabelecido pela Resolução CONAMA no 357/2005, em que a concentração de oxigênio dissolvido não deve ser inferior a $5,0 \mathrm{mg} \mathrm{L}^{-1}$, dessa forma, a montante do Rio Catolé em relação ao perímetro urbano para a variável OD, encontra-se na condição de qualidade água doce classe 2 , indicando a ocorrência de boa oxigenação, o que pode ser devido a produção de atividade fotossintética. Já ao longo do perfil estudado após a área urbana da cidade, encontrou-se um valor médio de 2,07 $\mathrm{mg} \mathrm{L}^{-1}$, podendo ser enquadrada em águas de classe 04. Este fato pode ser atribuído à decomposição de matéria orgânica (por oxidação) oriunda dos efluentes despejados diretamente no curso d'água. A baixa concentração de OD acusa o efeito deletério causado ao ecossistema pelo despejo dos resíduos provenientes das indústrias, dos esgotos e das redes pluviais, que são lançados no meio ambiente, na forma de líquidos ou de gases, os quais escurecem as águas e consomem oxigênio em sua decomposição.

De acordo com o teste de Tukey, realizado nos dois pontos de coleta, houve diferenças significativas nas variáveis, como pode ser observado na Tabela 2. 


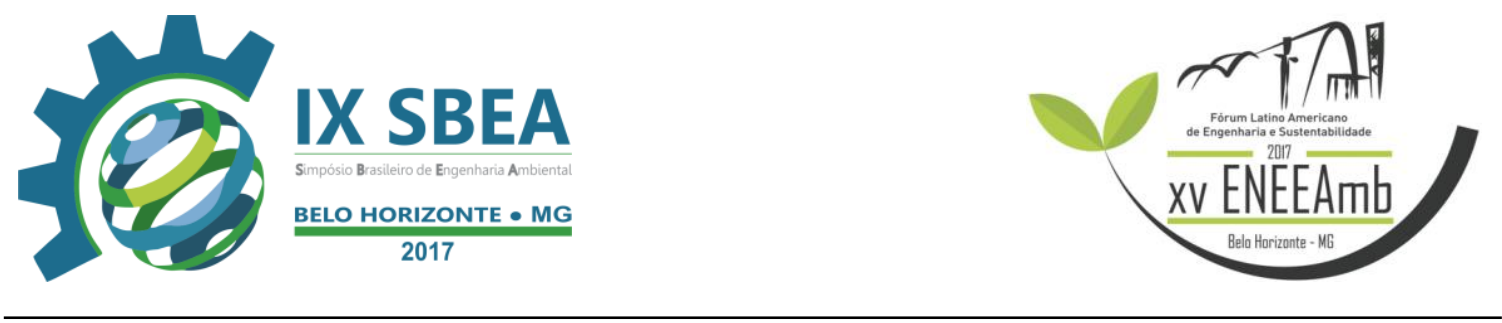

Tabela 2. Médias estimadas das variáveis em estudo, antes e após o perímetro urbano do município de Itapetinga.

\begin{tabular}{ccc}
\hline Variáveis & Ponto 1 & Ponto 2 \\
\hline pH & $8,46 \mathrm{a}$ & $7,78 \mathrm{~b}$ \\
Condutividade Elétrica (CE) & $97.76 \mathrm{a}$ & $123,77 \mathrm{~b}$ \\
Turbidez & $4,26 \mathrm{a}$ & $3,88 \mathrm{~b}$ \\
Sólidos Totais (ST) & $76,42 \mathrm{a}$ & $87,5 \mathrm{~b}$ \\
Oxigênio Dissolvido (OD) & $6,18 \mathrm{a}$ & $3,21 \mathrm{~b}$ \\
\hline
\end{tabular}

Médias seguidas por letras diferentes, nas linhas, diferem estatisticamente $(\mathrm{p}<0,05)$ pelo teste de Tukey.

De acordo com o teste de Tukey, realizado nos dois pontos de coleta, todas as variáveis diferiram estatisticamente a $5 \%$ de probabilidade entre os dois pontos. Essa diferença se deve principalmente aos efluentes lançados de forma arbitrária ao longo do rio, além do uso e a ocupação do solo na região está quase que estritamente restrito a atividades industriais e agropecuárias, que acarreta maiores cargas de poluentes para o ambiente lótico, tendo como consequências a deterioração do manancial e a redução da cobertura de água segura, isto é, escassez qualitativa.

\section{CONCLUSÕES/RECOMENDAÇÕES}

Diante o exposto, conclui-se que a CE e o OD no ponto após o perímetro urbano, se encontram fora dos padrões estabelecidos pela CETESB e CONAMA, respectivamente, sugerindo desequilíbrio ambiental, principalmente pelo despejo de efluentes, acusando o efeito deletério do ecossistema em questão. As demais variáveis ( $\mathrm{pH}$, turbidez e sólidos totais), apresentaram resultados satisfatórios antes e após o perímetro urbano. Todas as variáveis diferiram estatisticamente entre os dois pontos de coleta. 


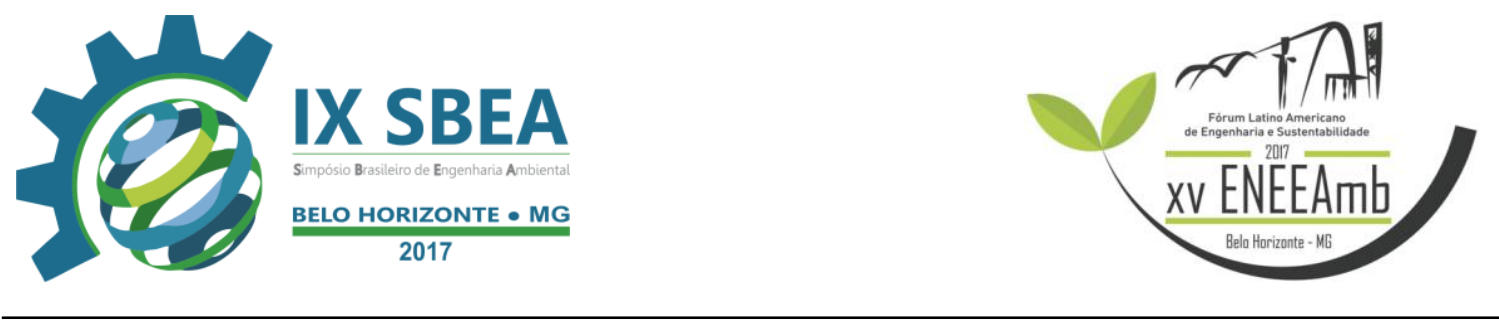

\section{REFERÊNCIAS BIBLIOGRÁFICAS}

APHA - AMERICAN PUBLIC HEALTH ASSOCIATION. Standard methods for the examination of water and wastewater. 19 Ed. New York: APHA, WWA, WPCR, 2005 .

BARRETO, L. V. Estado trófico em uma seção do rio Catolé Grande sob diferentes níveis de vazão. Itapetinga - BA, 57 p. (Mestrado em ciências ambientais). Universidade Estadual do Sudoeste da Bahia, 2013.

BARROS, V. G.; OLIVEIRA, B. G.; OLIVEIRA, T. M. N.; SANTOS, L. K.; NASS, D. N.; MACEDO, A. T.; MELO, Y. L.; MACEDO, A. T.; VIEIRA, C. V. Extremos físicoquímicos do rio cubatão norte - joinville, SC: a bacia nos ambientes urbano e rural. XIX Simpósio Brasileiro de Recursos Hidrícos. p. 1 - 16, 2011.

BISNAS, A. K. Monitoramento eficiente de lagos. Shiga: ONU, p. 541, 1990.

BRAGA, B.; HESPANHOL, I.; CONEJO, J. G. L.; MIERZWA, J. C.; BARROS, M. T. L.; SPENCER, M. et al. Introdução à engenharia ambiental. São Paulo: Prentice Hall, 2005.

BRASIL 2005. Resolução CONAMA (Conselho Nacional de Meio Ambiente). Resolução n. ${ }^{\circ}$ 357, de 17 de Março de 2005. Dispõe sobre a classificação dos corpos de água e diretrizes ambientais para o seu enquadramento, bem como estabelece as condições e padrões de lançamento de efluentes, e dá outras providências. Diário Oficial da República Federativa do Brasil, Brasília, 2005.

BRIGANTE, J.; ESPÍNDOLA, E.L.G. Limnologia Fluvial: Um estudo de caso no rio Mogi-Guaçu. São Carlos: RiMA, 2003.278p.

CETESB - Companhia de Tecnologia de Saneamento Ambiental do estado de São Paulo. Relatório de qualidade das águas superficiais de estado de São Paulo. Série Relatórios. São Paulo, 2009.

CETESB (Companhia de Tecnologia de Saneamento Ambiental do estado de São Paulo). Guia de coleta e preservação de amostras de água. São Paulo, CETESB, 1988.

GOMES, D. P. P.; ROCHA, F. A.; BARROS, F. M.; AMORIM, J. S. Avaliação de indicadores físico-químicos em uma seção transversal do rio Catolé em diferentes épocas. Enciclopédia Biosfera, v. 7, p. 1093-1098, 2011.

HU, H.; KIM, N.K. Drinking-water pollution and humanhealth. In: CHIVIAN, E. et al. (Ed.). Critical condition:human health and the environment. 2. Ed. EUA: MITPress, 1994. p. 31-45. 


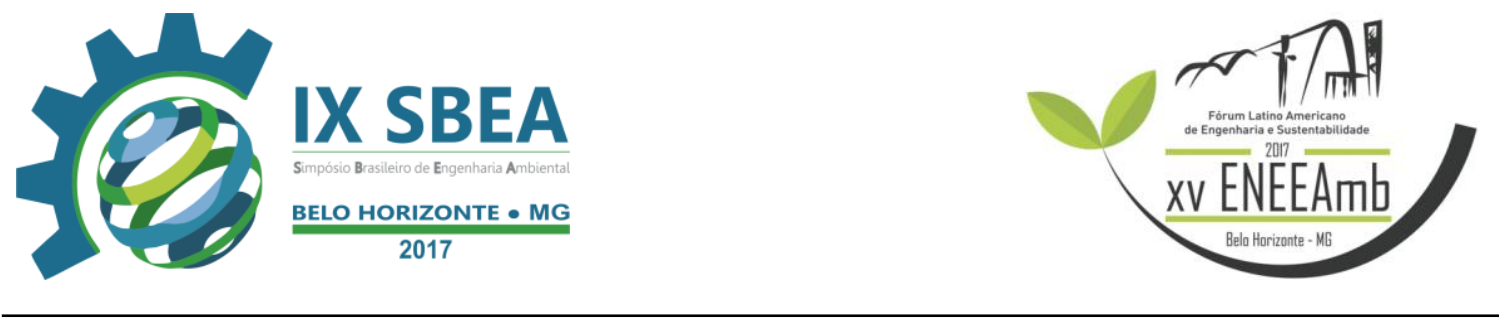

MATOS, A. T. de. Práticas de qualidade do meio físico e ambiental. Viçosa: AEAGRI. (Série Caderno Didático 34). 64p. 2004.

SARDINHA, D. S.; CONCEIÇÃO, F. T.; SOUZA, A. D. G.;SILVEIRA, A.; DE JULIO, M.;GONÇALVES, J. C. S.I. Avaliação da qualidade da água e autodepuração do Ribeirão do Meio, Leme (SP). Revista Brasileira de Engenharia Sanitária e Ambiental, v.13, n.3,p.329-338, 2008.

SILVA, Kartinalle Lima; AZEVEDO, Vivanny Carmem Fernandes de; LEITE, Eugênio Pacelli Fernandes. Mapeamento e Análise do Uso e Ocupação do Solo da Bacia do Rio Cuiá a Partir de Imagem do Satélite Quickbird. In: CONGRESSO NORTENORDESTE DE PESQUISA E INOVAÇÃO, 5, 2010, Maceió. Anais... Maceió, 2010.

VON SPERLING, M. V. Introdução a qualidade das águas e ao tratamento de esgotos. Belo Horizonte - MG. p. 243,1996.

WETZEL, R. G. Limnology: lake and river ecosystems. 3. ed. California: Academic Press, 2001. 